\section{A Case of Dysphonia}

\author{
Col RS Bhadauria*, Lt Col P Deb+, Maj A Karan"
}

MJAFI 2010; 66 : 78-79

Key Words : Dysphonia; Tuberculosis; Larynx; Phonoponosis

\section{Introduction}

$\mathrm{D}$ ysphonia implies difficulty in speaking. It is not unusual to find military instructors having hoarse voices and complaining of difficulty in speaking. This is attributed to improper use of the voice leading to overloading and abnormal adaptations of the cords. Most instructors are quite aware of this fact and also know that a period of rest restores the voice. If he is a smoker he occasionally reports to the otolaryngologist for a check up to exclude malignancy. We had one such case wherein a search for malignancy yielded surprising findings.

\section{Case Report}

A serving junior commissioned officer aged 45 years, employed as an instructor reported to the regimental medical officer with the complaints of inability to speak clearly for 20 days. The onset was sudden and he related it to an episode of drinking cold water. There was no history of fever, cough, haemoptysis, dysphagia or trauma. He was prescribed a course of antibiotics which produced no improvement, hence he reported to our centre on 04 Mar 08 . He was a cigarette smoker for the past 4 years smoking 5-6 cigarettes/day. He took alcohol occasionally. There was no history of tuberculosis, diabetes or hypertension.

General and systemic examinations were non contributory. ENT examination revealed a strained hoarse voice. Laryngeal crepitus was present. Indirect laryngoscopy (IDL) revealed grossly oedematous and inflamed vestibular bands. While the congested left vocal cord could be seen the right could not be visualized due to the oedematous vestibular band. Cord movements were normal. The patient was given a course of antibiotics once again along with antireflux medication and hospitalised for voice rest and further observation. He was also advised to stop smoking. All the relevant investigations which included screening for human immunodeficiency virus (HIV), ESR, blood sugar, thyroid function tests, radiographs of the paranasal sinuses and chest postero anterior (PA) view (Fig.1) were normal. Radiograph of soft tissue of neck with and without valsalva to exclude laryngocoele was also normal. On 12 Mar 08 he underwent upper gastrointestinal (UGI) endoscopy which revealed a small hiatus hernia and evidence of mild antral gastritis with duodenitis of the first part. He was advised to stop antibiotics but continue pantoprazole. After a week IDL showed that congestion had diminished but oedema persisted and patient did not report improvement. A non contrast computed tomography (NCCT) larynx to exclude any growth in the ventricles was done, which also did not show any significant abnormality.

As there was no improvement he was taken up for microscopic laryngeal examination and biopsy on 03 April 08 under general anaesthesia. This showed that the laryngeal mucosa was pale. Left vocal cord appeared slightly oedematous. Right vocal cord demonstrated a cystic looking swelling of superior surface with polypoid myxomatous appearance. Right vestibular band was grossly oedematous. Mucosa from the upper surface of the right vocal cord was stripped and sent for histopathological examination. This was processed in entirety as a single block. Epithelial lining was normal and examination for malignancy was negative but there was granulomatous inflammation favouring tuberculosis (Fig. 2). As radiograph of the chest (PA view) was normal a NCCT chest was now asked for to look for pulmonary tuberculosis. Three early morning specimens of sputum were also examined for acid fast bacilli (AFB). These were negative for AFB but CT scan of the chest (Fig. 3) showed a cavitary lesion in the posterior segment of the right upper lobe with surrounding fibrosis and a subcentimetre lymphadenopathy in the pre-tracheal region. The opinion of the radiologist was pulmonary tuberculosis. Antitubercular drugs were started immediately. The patient started showing rapid recovery with regression of the laryngeal oedema and restoration of his normal voice.

\section{Discussion}

Due to uncommon clinical presentations and lack of clinical suspicion, laryngeal tuberculosis (TB) is frequently confused with other laryngeal diseases such as chronic laryngitis and laryngeal carcinoma [1].

${ }^{*}$ Senior Advisor (ENT), MH Jabalpur. ${ }^{+}$Reader (Department of Pathology), AFMC Pune-40. ${ }^{*}$ Graded Specialist (ENT), Command Hospital (NC), C/o 56 APO.

Received : 09.09.08; Accepted : $30.09 .09 \quad$ E-mail : sdevrath@yahoo.com 


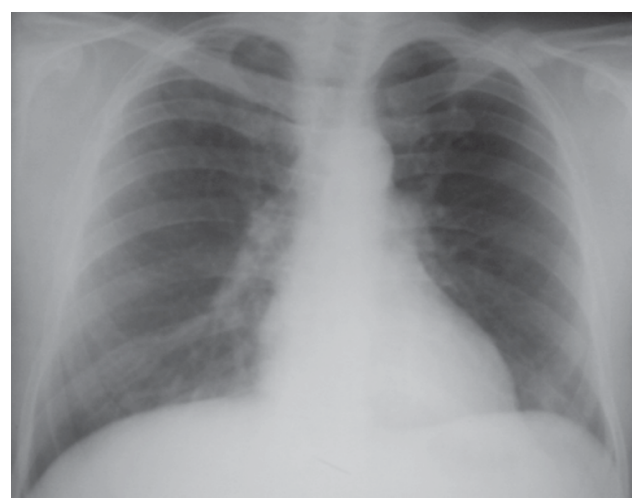

Fig. 1 : Chest radiograph (PA view)

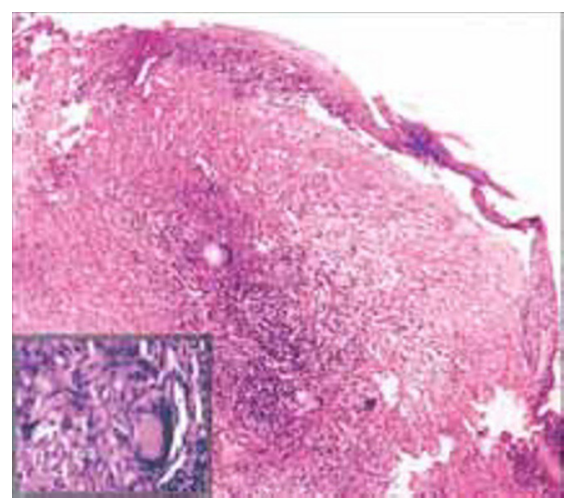

Fig. 2 : Laryngeal biopsy showing granulomatous inflammation (H\&E 100x) with epitheloid histiocytes \& Langhan's giant cell (Inset: H\&E 400x)

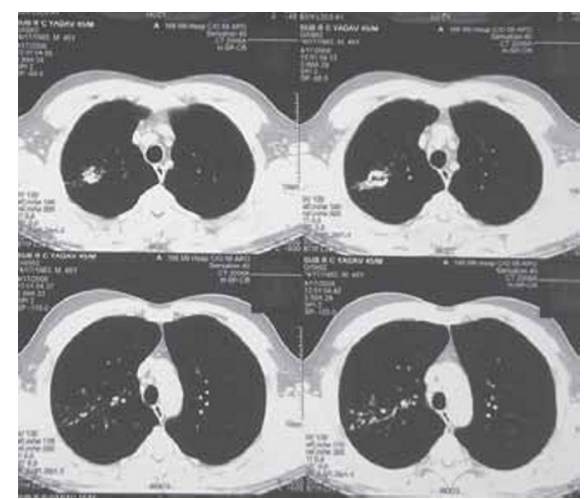

Fig. 3 : NCCT showing cavitary lesion in posterior segment of right upper lobe
Military instructors and the like with chronic laryngitis are particularly at risk from delay in diagnosis [2]. Anxiety about malignancy exists in smokers hence our patient reported early.

Radiograph chest (PA view) is a good method for screening pulmonary tuberculosis. However lesions affecting the posterior segment of the upper lobe may be missed. Routine chest radiography, which generally includes both PA and lateral views, is an integral part of the diagnostic evaluation of diseases involving the pulmonary parenchyma, the pleura and to a lesser extent, the airways and the mediastinum [3]. Since the patient did not have any symptoms pertaining to the respiratory system, lateral view chest was not taken. He also did not have any systemic features suggestive of pulmonary tuberculosis. This may be true in early course of post primary disease whence symptoms and signs are often nonspecific and insidious [4].

It is well known that laryngeal TB often masquerades as malignancy [5]. As laryngeal tuberculosis is always secondary to pulmonary tuberculosis, a chest radiograph and a sputum smear for AFB will be sufficient to confirm diagnosis. A biopsy is done in doubtful cases. In our case, biopsy yielded the diagnosis and further investigations established pulmonary tuberculosis.

Laryngeal TB is classically described to involve posterior half of the larynx, however this is a misconception and the true vocal cords are the most commonly affected site as was in our case $[6,7]$. For the same reason hoarseness is the most common symptom $(84.6 \%)$ [8].

As laryngeal tuberculosis is often found in patients suffering from open pulmonary tuberculosis, it could pose a serious risk to the public health and health care workers. The AFB may be found with special stains but are not always present, as in our case. It is assumed that in such cases the bacilli are carried via the submucus lymphatics or vascular networks from the site of pulmonary lesion.

The aim of this case report is to create awareness which helps in prompt diagnosis of laryngeal TB. It highlights the shortcomings of radiograph chest and that the pattern of involvement of the larynx may not be as classically described.

\section{Conflicts of Interest}

None identified

\section{References}

1. Lin CJ, Kang BH, Wang HW. Laryngeal tuberculosis masquerading as carcinoma. Eur Arch Otorhinolaryngol 2002; 259: 521-3.

2. Mackenzie K. Chronic Laryngitis. In: Hibbert J, editor. ScottBrown's Otorhinolaryngology, and head and neck surgery, Part 17. $7^{\text {th }}$ ed. London: Edward Arnold 2008; 2: 2266.

3. Weinberger SE, Drazen JM. Diagnostic procedures in respiratory disease. In : Kasper DL, Fauci AS, Longo DL, Braunwald E, Hauser SL, Jameson JL, editors. Harrison's Principles of Internal Medicine. $16^{\text {th }}$ ed. New York: Mc Graw Hill 2005; 1505.

4. Raviglione MC, O’Brian RJ. Tuberculosis. In : Kasper DL, Fauci AS, Longo DL, Braunwald E, Hauser SL, Jameson JL, editors. Harrison's Principles of Internal Medicine. $16^{\text {th }}$ ed. New York: Mc Graw Hill 2005; 956-7.

5. Harney M, Hone S, Timon C, Donnelly M. Laryngeal tuberculosis an important diagnosis. J Laryngol Otol 2000; 114: 878-80.

6. Koufman JA, Belafsky PC. Infectious and Inflammatory diseases of the larynx. In: Snow JB Jr, Ballenger JJ, editors. Ballenger's Otorhinolaryngology Head and Neck Surgery. $16^{\text {th }}$ ed. Hamilton: Decker BC; 2003; 1200.

7. Shin JE, Nam SY, Yoo SJ, Kim SY. Changing trends in clinical manifestations of laryngeal tuberculosis. Laryngoscope 2000; 110: 1950-3.

8. Wang CC, Lin CL, Wang CP, Liu SA, Jiang RS. Laryngeal tuberculosis: a review of 26 cases. Otolaryngol Head Neck Surg 2007; 137: 582-8. 